\title{
Prolonged Space-Wave Fadeouts in Tropospheric Propagation
}

\author{
Albrecht P. Barsis and Mary Ellen Johnson \\ Contribution From Central Radio Propagation Laboratory, National Bureau of Standards,
Boulder, Colo.
}

(Received May 3, 1962; revised June 12, 1962)

\begin{abstract}
This paper contains the results of studies performed during the last several years on the short-term variability of tropospheric signals received over within-the-horizon paths in Colorado and California. Signal variations of the type observed over such paths have been termed "prolonged space-wave fadeouts." They are analyzed as a function of carrier frequency, path characteristics, and meteorological parameters. The study also includes an evaluation of fadeouts observed over a path using a mountain peak as a diffracting knife-edge obstacle between transmitter and receiver.

Principal results show a stronger diurnal trend of fadeout incidence in continental climates than in maritime climates. A significant dependence of the fadeout characteristics on the refractive index structure has been observed in maritime climates.

In general, fadeouts tend to be more frequent but of shorter duration for higher frequencies. There are also indications that the occurrence of fadeout is well correlated on vertically spaced antennas. Thus, conventional space diversity techniques may not be effective to increase the reliability of systems operating over within-the-horizon paths.
\end{abstract}

\section{Introduction}

A recent NBS Technical Note [Barsis and Johnson, 1961] contained detailed results on measurements of short-term fading characteristics observed over within-the-horizon paths at frequencies between 100 and $1250 \mathrm{Mc} / \mathrm{s}$. These data have been re-analyzed in part and are presented here. Short-term signal variations on within-the-horizon paths have previously been defined and analyzed as "space-wave fadeouts" [Bean, 1954], if they were characterized by a drop in signal level to at least five decibels below the monthly median signal for at least one minute's duration. The term "space-wave fadeouts" is used in the present analysis, although for some of the data improved recording methods permitted the measurement of fadeouts as short as $0.1 \mathrm{~min}$, and in some instances fadeouts much longer than $1 \mathrm{hr}$ have been observed, so that one cannot classify this phenomenon as strictly "short-term." However, the analysis considers fading characteristics which differ from those commonly observed over tropospheric scatter paths in the distributions of instantaneous signal envelope levels, which are usually not representable by a Rayleigh distribution, or by combining a steady with a Rayleigh distributed signal. The variations are also much slower than the fading on tropospheric scatter paths.

Tropospheric "obstacle-gain" paths which employ knife-edge diffraction exhibit fadirg characteristics very similar to two line-of-sight paths in tandem. Recently space-wave fadeouts and other fading phenomena were observed on such an obstacle-gain propagation path which uses a mountain as a diffracting obstacle between the path terminals [Barsis and Kirby, 1961].

Detailed descriptions including terrain profiles, antenna heights, and other data for all propagation paths which were used in the fadeout study are contained in the NBS Technical Note [Barsis and Johnson, 1961]. Two of the paths (including the knife-edge diffraction or obstacle-gain path) were located in Eastern Colorado, which represents a continental, dry climate. Two others were along the coast in Southern California, which represents a maritime climate with almost constantly present refractive index stratification. This is indicated by the well-known elevated subsidence inversion observed in the summer months.

Table 1 summarizes various characteristics of the propagation paths and measurements for easier reference.

TABLE 1. Characteristics of paths and propagation measurements used in the study of prolonged space-wave fadeouts

\begin{tabular}{|c|c|c|c|c|}
\hline Path designation & Location & Length & $\begin{array}{c}\text { Carrier } \\
\text { frequency }\end{array}$ & $\begin{array}{l}\text { Path and climate } \\
\text { characteristics }\end{array}$ \\
\hline $\begin{array}{l}\text { Cheyenne Mt.- } \\
\text { Karval }\end{array}$ & $\begin{array}{l}\text { Eastern } \\
\text { Colorado }\end{array}$ & $\begin{array}{l}\mathrm{km} \\
113\end{array}$ & $\begin{array}{l}M c / s \\
1046\end{array}$ & $\begin{array}{l}\text { Line-of-sight, dry, } \\
\text { continental }\end{array}$ \\
\hline $\begin{array}{l}\text { Beulah-Table } \\
\text { Mesa }\end{array}$ & $\begin{array}{l}\text { Eastern } \\
\text { Colorado }\end{array}$ & 223 & 751 & $\begin{array}{l}\text { Obstacle-gain, dry, } \\
\text { continental }\end{array}$ \\
\hline $\begin{array}{l}\text { Mt. Wilson-Pt. } \\
\text { Loma }\end{array}$ & $\begin{array}{l}\text { Southern } \\
\text { California }\end{array}$ & 185 & $\begin{array}{l}138, \\
1250\end{array}$ & $\begin{array}{l}\text { Line-of-sight, } \\
\text { maritime }\end{array}$ \\
\hline $\begin{array}{l}\text { San Nicolas } \\
\text { Island-Laguna } \\
\text { Peak }\end{array}$ & $\begin{array}{l}\text { Southern } \\
\text { California }\end{array}$ & 104 & $\begin{array}{l}100 \\
250 \\
400\end{array}$ & $\begin{array}{l}\text { Line-of-sight, } \\
\text { maritime }\end{array}$ \\
\hline
\end{tabular}

\section{Definition of Prolonged Space-Wave Fadeouts}

The study of fadeout phenomena requires first a definition of the term "space-wave fadeout" and its distinction from the term "fading" commonly employed. "Fading" usually refers to the rapid amplitude variations of a radio signal transmitted over relatively long distances through the troposphere or the ionosphere. In the case of long-distance tropospheric scatter propagation, the rapid fading is 
presumably caused by the vector addition of a large number of field components arriving at the receiving location with random phase. The amplitude distribution of such a signal tends to have the form of a Rayleigh distribution, and the fading rate with reference to a short-term average or median value varies with carrier frequency, atmospheric conditions, and path length approximately within the limits of 0.1 to $10 \mathrm{c} / \mathrm{s}$.

As implied by its name, the term "prolonged space-wave fadeout" is restricted to paths where the geometric-optics space-wave is predominant; it may also be applied to knife-edge diffraction paths. The fading rate is extremely slow relative to fading rates observed, for instance, on tropospheric scatter paths, and the amplitude distribution of the received signal cannot usually be represented by a Rayleigh, or any other simple distribution function. Fadeouts of this type may be caused by vector addition of a few specular components caused by reflection from layers, or a defocusing of energy by layers and similar phenomena, which tend to shift with the variable refractive index structure of the lower atmosphere, thus causing the variations in signal level. Possible small contributions to the received field due to scatter are neglected in this analysis. Figure 1 shows a typical space-wave fadeout. The depth $D$ of the fadeout is measured with reference to an arbitrary signal level, which is usually a long-term median of hourly median values. The same reference level is $R$ decibels above the RMS receiver noise level. The quantity

$$
R_{D}=R-D
$$

is then the instantaneous carrier envelope signal-toRMS noise ratio. It may, as an example, be used to estimate performance characteristics for communication links using paths of this type.

The definition of space-wave fadeouts was restricted to those fadeouts which extend to at least $5 \mathrm{db}$ below the reference level. In Bean's original work [1954] and some of the earlier analyses, fadeouts of less than $1 \mathrm{~min}$ duration at the 5 -db level were neglected due to the time-scale of the available records. This restriction was removed in later work where it was possible to measure fadeouts of shorter duration more accurately, and, at the same time, to eliminate scintillation-type fades ascribed to a scatter component.

As some fadeouts have been observed to last longer than one hour, the term "short-term variations" is not strictly applicable. For the purpose of the analysis in this paper the term "prolonged space-wave fadeout" applies to all observed signal variations relative to at least a weekly and preferably a monthly median field strength value neglecting the superimposed scintillating-type fading of small amplitude which is thought to be caused by tropospheric scatter.

In this paper fadeout incidence and fadeout duration will be discussed, and their dependence on carrier frequency and atmospheric characteristics explored. Fadeout incidence, the number of fadeouts observed within a given time period regardless of their dura- tion, is useful in studies of diurnal and seasonal variations, and their dependence on meteorological phenomena. Fadeout duration is the length of time the signal drops below a given level (or the transmission loss exceeds a given level) during an individual fadeout, and the cumulative distribution of fadeout duration at various levels below a median reference level is of interest.

\section{Comparison of Fadeout Characteristics for Continental and Maritime Climates}

In this comparison, the 113-km Cheyenne Mountain-Karval path in Eastern Colorado and the 185$\mathrm{km}$ Mount Wilson-Point Loma path in Southern California are used, as data on similar frequencies (1046 and $1250 \mathrm{Mc} / \mathrm{s}$ ) are available for them. Additionally, data at $138 \mathrm{Mc} / \mathrm{s}$ are available for the Southern California path. Both paths are completely line-of-sight, i.e., within the radio horizon, and a minimum fadeout duration of $1 \mathrm{~min}$ was used. Fadeout studies for the Colorado path are based on data obtained in 1952 and 1953, with important results based on the first year of operation already reported by Bean [1954]. He concluded from an analysis of the dependence of these fadeouts on meteorological characteristics that fadeouts are more likely to occur whenever a ground-modified refractive index profile was observed. Fadeouts are not observed as frequently whenever linear refractive index profiles characteristic of a well-mixed atmosphere are present.

Simultaneous measurements on 100 and $200 \mathrm{Mc} / \mathrm{s}$ over the Colorado path showed very few fadeouts on these lower frequencies during both years-not enough to perform an analysis. This is the first significant result of this comparative study, as the maritime climate of the Southern California path produced a substantial number of fadeouts on 138 $\mathrm{Mc} / \mathrm{s}$, and will be further discussed in section 6 below.

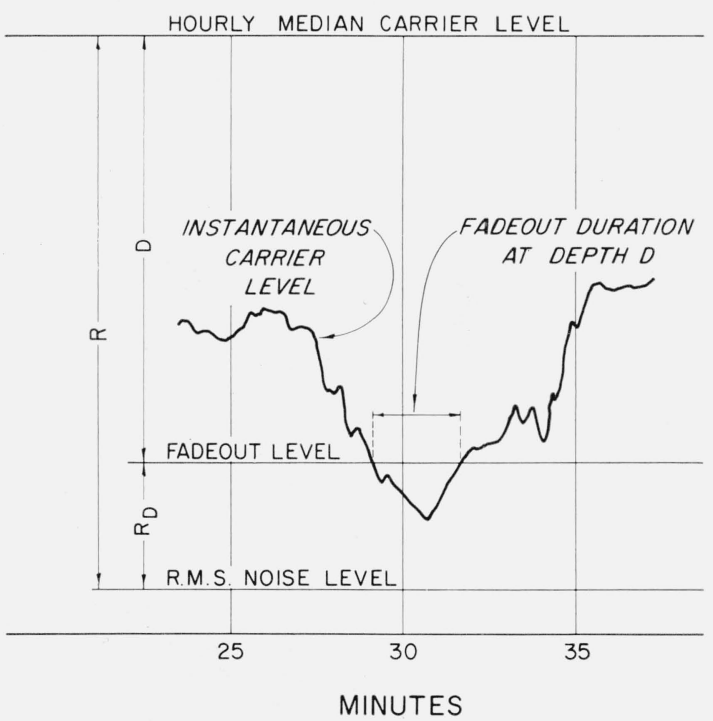

Figure 1. Typical prolonged space-wave fadeout. 
Data for the Mount Wilson-Point Loma path are available for several months during 1950 and 1951 .

The diurnal variation of 5 -db fadeout incidence is shown on figure 2 for both paths. The abscisse scale indicates the individual hours of the day as well as the "time blocks," as defined by Norton, Rice, and Vogler [1955]. Whereas the data for the continental eastern Colorado path show a minimum of fadeouts during the daylight hours, especially around noon, the southern California data representing a maritime climate show less diurnal variation, with a maximum fadeout incidence during the early afternoon hours. There are also more fadeouts on the maritime path than on the continental path, if the normalized fadeout incidence of the frequencies in the $1000 \mathrm{Mc} / \mathrm{s}$ range is compared. It will be seen later that the fadeouts on the California path are generally shorter in duration. Comparing diurnal trends at 138 and $1250 \mathrm{Mc} / \mathrm{s}$ for the California path, it is seen that they are quite similar.

Figure 3 indicates a pronounced seasonal trend of fadeout incidence for the Colorado data, with a maximum during the summer months. There are not enough data available for the California path to establish a seasonal trend from the appearance of the graphs on figure 3, either at 1250 or at $138 \mathrm{Mc} / \mathrm{s}$.

Durations of fadeouts are compared on figure 4 for the two paths. Cumulative distributions are shown here of fadeouts to the 5,10 , and $15 \mathrm{db}$ level below the monthly transmission loss medians for the frequencies in the $1000 \mathrm{Mc} / \mathrm{s}$ range. It is seen that the fadeouts are significantly shorter for the California path. The total number of fadeouts used for the analysis is indicated for each curve shown.

A similar comparison is given on figure 5 for 138 and $1250 \mathrm{Mc} / \mathrm{s}$, both for the California path, showing that fadeouts are more numerous and shorter at the higher frequency.

Table 2 summarizes data read from figures 4 and 5 .

TABLE 2. Comparison of median fadeout durations and durations exceeded by 10 percent of all fadeouts

\begin{tabular}{l|c|c|c}
\hline \hline & \multicolumn{2}{|c}{ Fadeout durations exceeded, in minutes } \\
\cline { 2 - 2 } & $\begin{array}{c}\text { Colorado Path } \\
1046 \mathrm{Mc} / \mathrm{s}\end{array}$ & \multicolumn{2}{|c}{ California Path } \\
& & $1250 \mathrm{Mc} / \mathrm{s}$ & $138 \mathrm{Mc} / \mathrm{s}$ \\
\cline { 2 - 3 } & & & \\
& 5.8 & 2.3 & 6.2 \\
Median fadeout durations: & 5.0 & 1.6 & 5.7 \\
$5 \mathrm{db}$ level & 2.9 & 1.1 & 3.5 \\
$10 \mathrm{db}$ level & & & \\
15 db level & 38 & 10.2 & 49 \\
Duration of $10 \%$ of all fadeouts: & 26 & 6.8 & 38 \\
5 db level & 15.5 & 3.9 & 20 \\
10 db level & & & \\
15 db level & & & \\
\hline
\end{tabular}

The receiving antenna used for the eastern Colorado path during 1952 and 1953 was mounted $13 \mathrm{~m}$ above ground. Data obtained during December 1953 included simultaneous measurements using antennas at 1.5 and $4.3 \mathrm{~m}$ above ground in addition to the one at $13 \mathrm{~m}$. Thus, vertical spacings between approximately 10 and 40 wavelengths are represented.

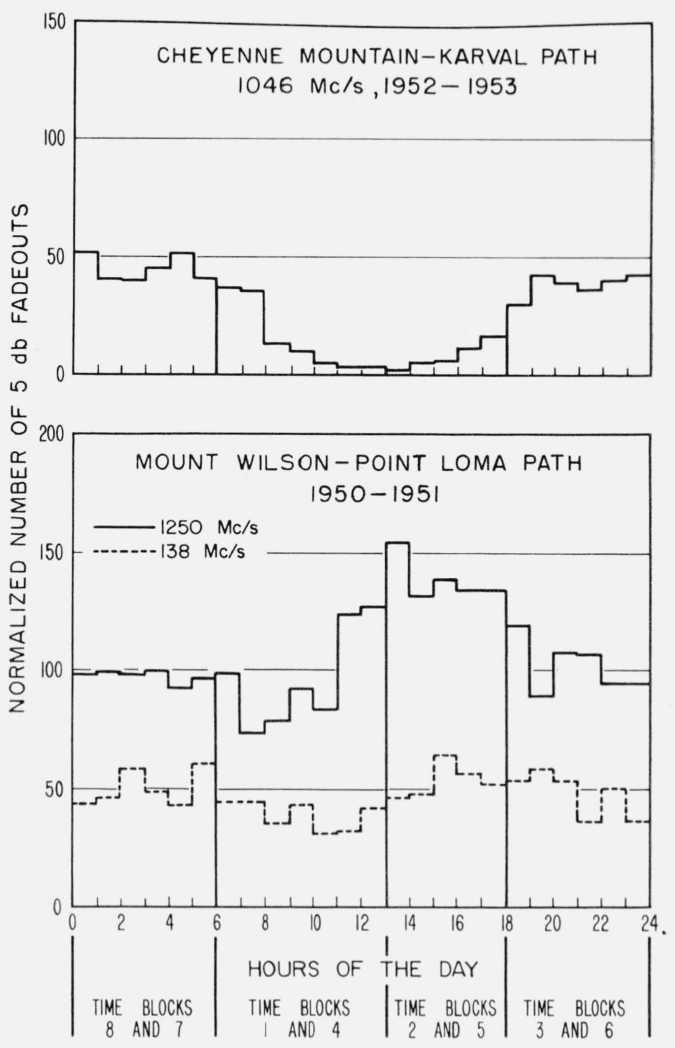

FIgURE 2. Diurnal variations of prolonged space-wave fadeouts.

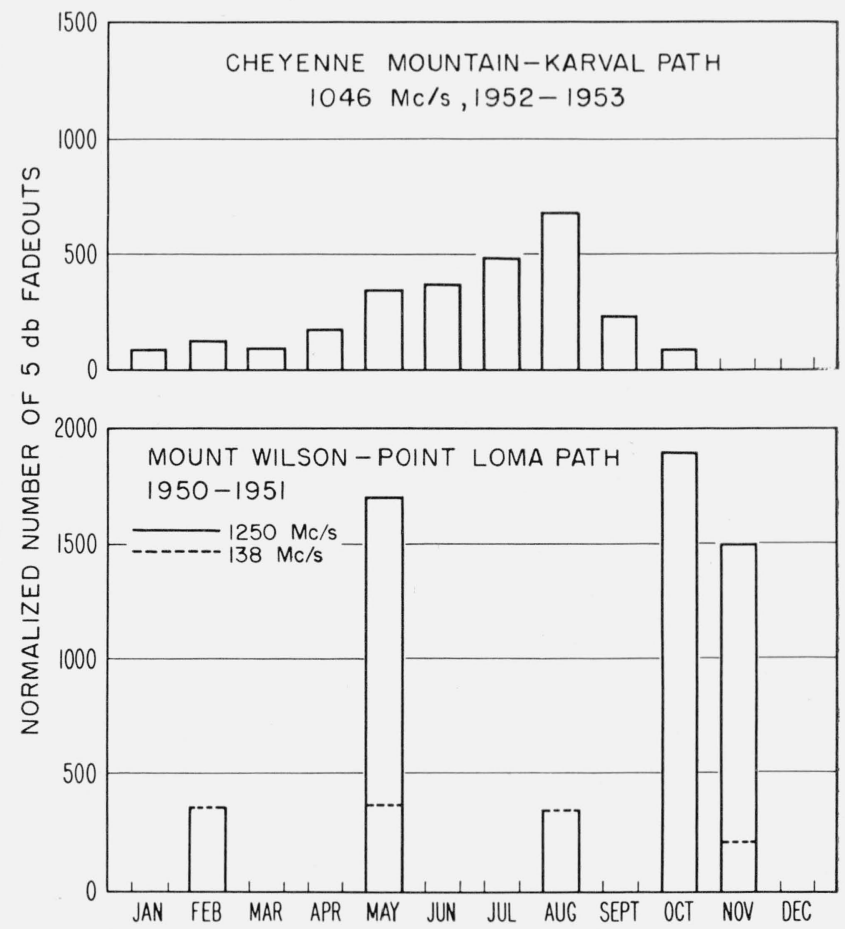

FIGURE 3. Month-to-month variation of prolonged space-wave fadeouts. 


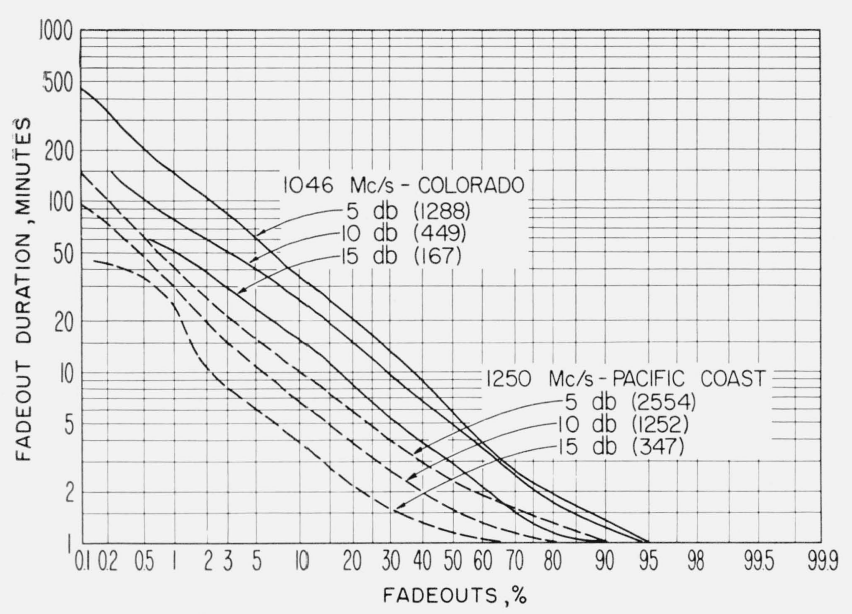

Figure 4. Geographical variation of fadeout duration distributions (Pacific Coast, 1950-1951, and Eastern Colorado, 1952-1953).

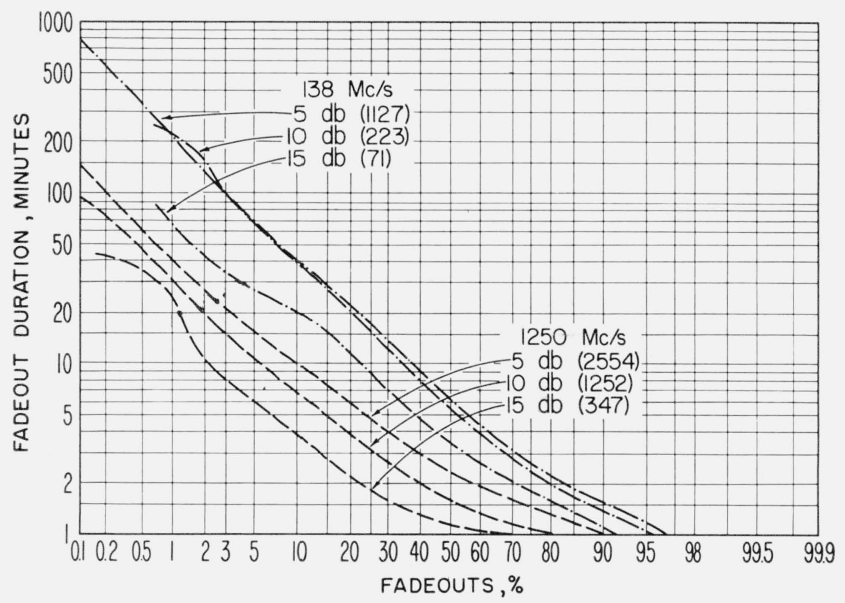

Figure 5. Frequency dependence of fadeout duration distributions for Mount Wilson-Point Loma path, 1950-1951.

Figure 6 shows a sample of recording charts for the three antenna heights at the time of a fadeout. The fadeout characteristics appear to be extremely well correlated in time. The "transmitter-off", period in the record provides an accurate check on the synchronization of the records for use in correlating fadeouts. The small, more rapid signal variations superimposed on the recording traces are not considered in this analysis.

During this December 1953 measurement period, $322 \mathrm{hr}$ of data were recorded simultaneously using all three receiving antennas. Table 3 summarizes the 5-db and 10-db fadeout statistics for these hours.

The total fadeout time in table 3 is the number of minutes the signal remained at or below the 5 - $\mathrm{db}$ or 10-db level, respectively, during the $322 \mathrm{hr}$ recorded. It is seen that there are about twice as many fadeouts on the highest antenna than on each of the two lower ones and that the total fadeout time is also significantly larger on the highest $(13 \mathrm{~m})$ of the three antennas, but the minimum fadeout time appears to be on the 4.3-m antenna. Thus fadeout incidence and fadeout time are not necessarily functions of
TABLE 3. Fadeout statistics, Eastern Colorado Path $1046 \mathrm{Mc} / \mathrm{s}$, December 1953

\begin{tabular}{|c|c|c|c|c|}
\hline \multirow{2}{*}{$\begin{array}{c}\text { Antenna } \\
\text { height } \\
\text { above } \\
\text { ground }\end{array}$} & \multicolumn{2}{|c|}{ 5-db fadeouts } & \multicolumn{2}{|c|}{ 10-db fadeouts } \\
\hline & $\begin{array}{c}\text { Total } \\
\text { number }\end{array}$ & $\begin{array}{c}\text { Total } \\
\text { fadeout } \\
\text { time }\end{array}$ & $\begin{array}{c}\text { Total } \\
\text { number }\end{array}$ & $\begin{array}{c}\text { Total } \\
\text { fadeout } \\
\text { time }\end{array}$ \\
\hline 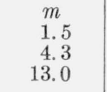 & $\begin{array}{l}36 \\
30 \\
75\end{array}$ & $\begin{array}{r}\min \\
771 \\
488 \\
1528\end{array}$ & $\begin{array}{r}7 \\
5 \\
14\end{array}$ & $\begin{array}{c}\min \\
66 \\
29 \\
182\end{array}$ \\
\hline
\end{tabular}

antenna height, but may also depend on the geometrical characteristics of the foreground and possibly the thickness of ground-modified layers.

For the purpose of estimating the effectiveness of vertical diversity, a study was made of the number of instances when 5-db and 10-db fadeouts occured simultaneously on pairs of antennas or on all three of them. Simultaneous fadeouts mean that any portion of the fadeouts observed on the antennas considered coincided in time. Results are given in table 4.

\begin{tabular}{|c|c|c|}
\hline \multirow{3}{*}{$\begin{array}{l}\text { Antenna combina- } \\
\text { tions: } \\
1.5 \text { and } 4.3 \mathrm{~m} \\
1.5 \text { and } 13 \mathrm{~m} \\
4.3 \text { and } 13 \mathrm{~m} \\
\text { all antennas }\end{array}$} & \multicolumn{2}{|c|}{$\begin{array}{l}\text { Number of fadeouts observed } \\
\text { simultaneously on the an- } \\
\text { tenna combinations listed at } \\
\text { left }\end{array}$} \\
\hline & $5 \mathrm{db}$ & $10 \mathrm{db}$ \\
\hline & $\begin{array}{l}25 \\
27 \\
24 \\
19\end{array}$ & $\begin{array}{l}5 \\
6 \\
5 \\
5\end{array}$ \\
\hline
\end{tabular}

Additional analyses of the data given above are contained in the Technical Note [Barsis and Johnson, 1961], and lead to qualitative estimates of the effectiveness of vertical space diversity. One may conclude that for installations of this type there is at least a 30 percent probability that $10-\mathrm{db}$ fadeouts occur simultaneously on three vertically spaced antennas. It is also seen that there are substantially more fadeouts on a high antenna, but with greater correlation between fadeouts occurring simultaneously on the two lower antennas.

Cumulative distributions of the durations of $5-\mathrm{db}$ and $10-\mathrm{db}$ fadeouts for all three antenna heights, using all data available for December 1953, were also obtained and plotted. From these graphs the median fadeout duration, and the duration of 10 percent of all fadeouts are tabulated below.

TABle 5. Fadeout durations for December 1953 Cheyenne Mountain-Karval Path $1046 \mathrm{Mc} / \mathrm{s}$

\begin{tabular}{c|c|c|c|c}
\hline \hline \multirow{2}{*}{$\begin{array}{c}\text { Antenna } \\
\text { height }\end{array}$} & \multicolumn{2}{|c|}{$\begin{array}{c}\text { Duration of median } \\
\text { fadeout }\end{array}$} & \multicolumn{2}{c}{$\begin{array}{c}\text { Duration of } 10 \% \text { of } \\
\text { all fadeouts }\end{array}$} \\
\cline { 2 - 3 } & $5 \mathrm{db}$ & $10 \mathrm{db}$ & $5 \mathrm{db}$ & $10 \mathrm{db}$ \\
& & & & \\
1.5 & $\min$ & $\min$ & $\min$ & $\min$ \\
4.3 & 10.6 & 3.5 & 39 & 20.5 \\
13.0 & 6.4 & 5.7 & 45 & 18.5 \\
& & 5.0 & 60 & 56.0 \\
\hline
\end{tabular}



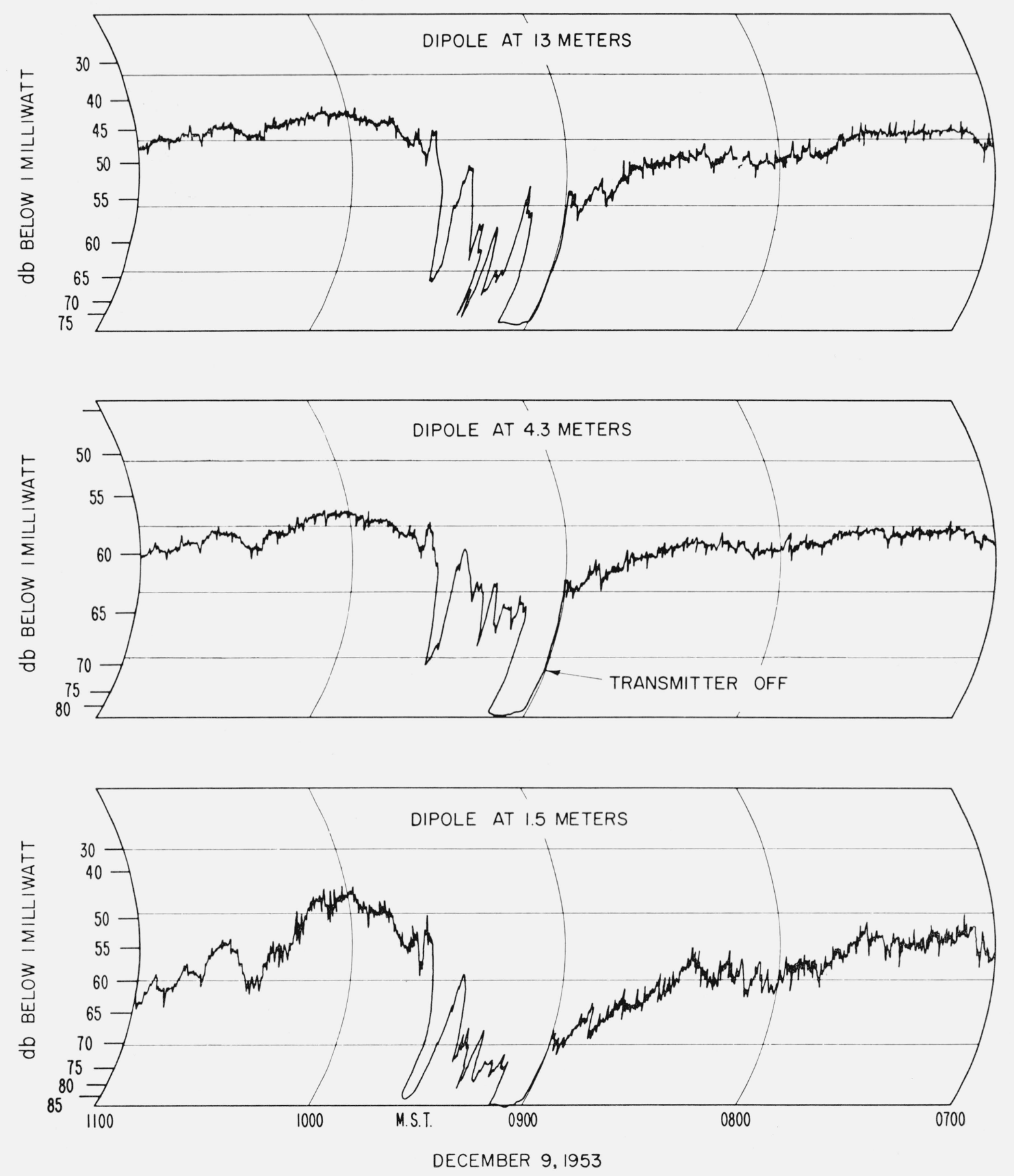

Figure 6. Recording chart samples for Cheyenne Mountain-Karval path; $1046 \mathrm{Mc} / \mathrm{s}$.

The median fadeout duration at the 5-db level, tends to be shortest for the highest antenna. However, 10 percent of the fadeouts for this antenna are quite long-about $1 \mathrm{hr}$. The median fadeout duration at the $10-\mathrm{db}$ level is relatively short for the lowest antenna.

\section{San Nicolas Island-Laguna Peak Path (Southern California)}

Additional data for the Southern California maritime climate were provided by a joint propagation study by the Naval Air Missile Test Center, Point 
Mugu, California, and the National Bureau of Standards. Meteorological data to support the transmission loss measurements were supplied by the U.S. Naval Air Station at Point Mugu. The path profiles, operational details, and analysis method were described by Barsis and Johnson [1961] and in an earlier paper by Barsis and Capps [1957], which contains important results of this program. These, and additional data evaluated since, form the basis for a study of space-wave fadeouts and their dependence on path and meteorological parameters. Minimum fadeout durations as short as $0.1 \mathrm{~min}$ were considered here, and the following approach was used.

(a) Evaluation of two years radio data on 394 $\mathrm{Mc} / \mathrm{s}$, including correlation of the observed fadeout phenomena with refractive index profile types.

(b) Comparison of fadeout data at the three frequencies (approximately 100, 250, and 400 $\mathrm{Mc} / \mathrm{s}$ ) for typical winter and summer months.

(c) Comparison of fadeout data for two receiving sites within the radio horizon which are widely separated in elevation.

It will be appropriate to discuss first the evaluation of the meteorological data, and the classification of the refractive index profiles. The data supplied by the Point Mugu Naval Air Station included pseudo- adiabatic charts from radiosonde ascents at San Nicolas Island and at Point Mugu, as well as surface observations of temperature, barometric pressure, and relative humidity. From these data the refractivity was computed and plotted in the form of curves of a modified refractive index " $A$ " as a func tion of height as defined by Bean et al. [1959]. Values of the surface refractivity were determined as well. Further details are given by Barsis and Johnson [1961]. This paper also contains typical samples for and a definition of the five types of refractive index profiles used.

Figure 7 is an illustration of the effect of the refractive index profiles on the character of the received signal. Two chart samples of the Laguna Peak record representing the within-the-horizon path are shown. The upper record, taken at a time when a linear refractive index profile was observed at Point Mugu, shows a virtually constant signal over a period of several hours. The lower record corresponds to a time when ground-based layers were observed at Point Mugu and shows very substantial space-wave fadeouts.

Table 6 shows the relative frequency of occurrence of the various profile types at both sounding locations during the period November 1955 to October 1957. It is not possible to distinguish between "ground-

(a) Linear Refractive Index Profile, No Space-Wave Fadecuts

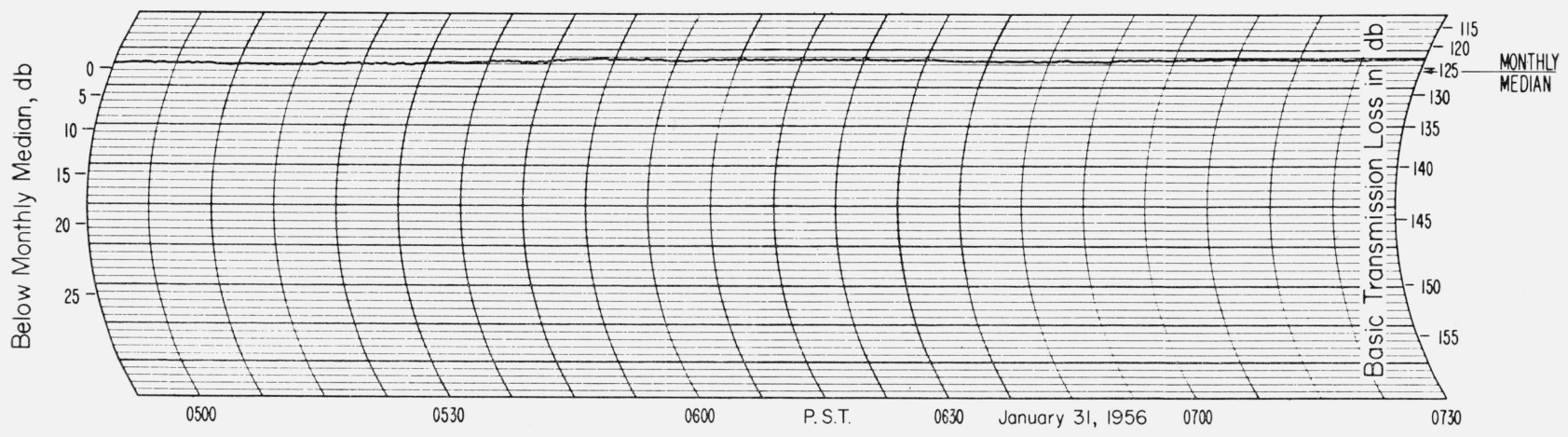

(b) Refractive Index Profile Characterized by a Ground Based Layer, Pronounced Space -Wave Fadeouts

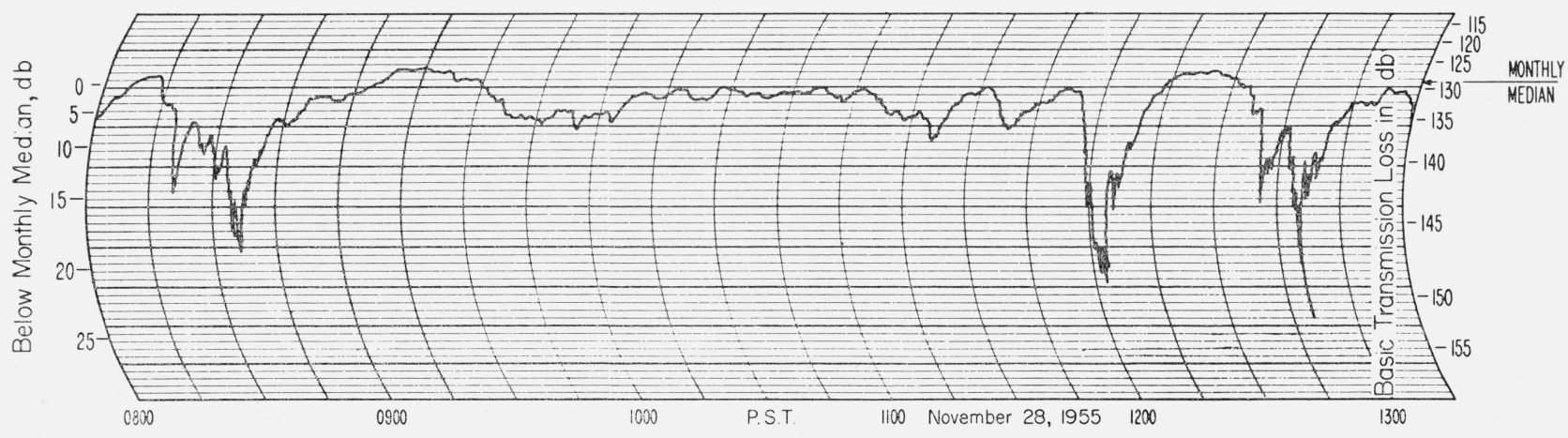

Figure 7. Recording chart samples for San Nicolas Island-Laguna Peak path; $394 \mathrm{Mc} / \mathrm{s}$. 
TABLE 6. Occurrence of various profile types from November 1955 to October $195 \%$

\begin{tabular}{|c|c|c|c|c|c|}
\hline \multirow{2}{*}{\multicolumn{2}{|c|}{$\begin{array}{l}\text { Profile type and total } \\
\text { number observed }\end{array}$}} & \multicolumn{2}{|c|}{$\begin{array}{l}\text { Number of times } \\
\text { observed }\end{array}$} & \multicolumn{2}{|c|}{$\begin{array}{l}\text { Percentage of total } \\
\text { observations }\end{array}$} \\
\hline & & Pt. Mugu & $\begin{array}{l}\text { San Nicolas } \\
\text { Island }\end{array}$ & Pt. Mugu & $\begin{array}{l}\text { San Nicolas } \\
\text { Island }\end{array}$ \\
\hline $\begin{array}{l}\text { Linear } \\
\text { High elevated layer } \\
\text { Medium elevated layer } \\
\text { Low elevated layer } \\
\text { Ground based layer } \\
\quad \text { Totals: }\end{array}$ & $\begin{array}{r}93 \\
55 \\
117 \\
395 \\
669\end{array}$ & $\begin{array}{r}66 \\
28 \\
62 \\
52 \\
93 \\
301\end{array}$ & $\begin{array}{r}27 \\
27 \\
55 \\
250 \\
359\end{array}$ & $\begin{array}{r}21.9 \\
9.3 \\
20.6 \\
17.3 \\
30.9\end{array}$ & $\begin{array}{r}7.5 \\
7.5 \\
15.3 \\
69.7\end{array}$ \\
\hline
\end{tabular}

based" (GB) and "low elevated" (LE) layers for profiles observed at San Nicolas Island. The radiosonde measurements were conducted from an airstrip located about $170 \mathrm{~m}$ above sea level, which is close enough to the coast so that sea level can be taken as the actual reference.

It is quite evident that profiles characterized by layers below $1000 \mathrm{~m}$ predominate; actually more than half of all observations indicate layers below the 500-m level, thus placing both path terminals for the propagation studies below the layers. In the study of the effects of layer height on the propagation characteristics, profiles observed at both sounding locations will be used. Of all observations there were only 96 radiosonde ascents taken approximately simultaneously at both locations (within about $1 \frac{1}{2} \mathrm{hr}$ ). Out of this total, 62, or somewhat more than one-half, showed the same profile type in accordance with the classification used. Although this does not fully support the assumption of complete equivalence of the profiles obtained at the two locations, it does permit the use of all profiles, regardless of their origin, for further analysis.

For the study of fadeout dependence on profile types, the $394 \mathrm{Mc} / \mathrm{s}$ data for the path San Nicolas Island-Laguna Peak Summit were used for the period November 1955 to October 1957. Within this period approximately $14,000 \mathrm{hr}$ of good data were obtained. However, in the study of fadeout dependence on refractive index profile types, only those data were used which fell within the three hour period centered on the time of the radiosonde ascent. Soundings were usually taken around $8 \mathrm{a} . \mathrm{m}$. local time (in some instances additional soundings were taken between noon and 4 p.m.).

In this particular analysis, fadeout incidence is the number of times fadeouts are observed concurrently with a specific type of refractive index profile, and fadeout time is the total time the signal remained at least 5 or $10 \mathrm{db}$ below the monthly median, but both quantities are expressed in percent of the 3-hr time period centered on the radiosonde ascent. Results of the analysis are given in table 7 .

This tabulation shows that both fadeout incidence and fadeout time are functions of the profile type. Substantially more fadeouts and more fadeout time were observed at the 5- and the 10-db level for the low elevated and ground-based layers than for the other types. The various combinations of profile types used in table 7 show that the effect of medium-
TABLE 7. Fadeout characteristics versus refractive index profile types for San Nicolas Island-Laguna Peak (Summit) path on $394 \mathrm{Mc} / \mathrm{s}$, November 1955 to October 1957

\begin{tabular}{|c|c|c|c|c|c|}
\hline \multirow[t]{2}{*}{ Profile type } & \multirow{2}{*}{$\begin{array}{c}\text { Total } \\
\text { number } \\
\text { of ob- } \\
\text { served } \\
\text { profiles }\end{array}$} & \multicolumn{2}{|c|}{$\begin{array}{l}\text { Percentage of } \\
\text { fadidout } \\
\text { incidence }\end{array}$} & \multicolumn{2}{|c|}{$\begin{array}{l}\text { Percentage of } \\
\text { fadeout } \\
\text { time }\end{array}$} \\
\hline & & $5 \mathrm{db}$ & $10 \mathrm{db}$ & $5 \mathrm{db}$ & $10 \mathrm{db}$ \\
\hline $\begin{array}{l}\text { Linear }(\mathrm{L}) \\
\text { High elevated layer (HE) } \\
\text { Medium elevated layer }(\mathrm{ME}) \\
\text { Jow elevated layer (LE) } \\
\text { Ground based layer (GB) } \\
\text { L+HE } \\
\text { ME+LE+GB } \\
\text { L+HE+ME } \\
\text { LE+GB } \\
\text { All profiles }\end{array}$ & $\begin{array}{r}93 \\
55 \\
117 \\
302 \\
93 \\
148 \\
512 \\
265 \\
395 \\
660\end{array}$ & $\begin{array}{l}32.3 \\
16.4 \\
30.1 \\
70.2 \\
66.7 \\
26.4 \\
60.6 \\
28.3 \\
69.4 \\
52.9\end{array}$ & $\begin{array}{r}18.3 \\
7.3 \\
18.8 \\
50.0 \\
51.6 \\
14.2 \\
43.2 \\
16.2 \\
50.4 \\
36.7\end{array}$ & $\begin{array}{r}10.7 \\
5.3 \\
6.9 \\
20.9 \\
19.9 \\
8.7 \\
17.5 \\
7.9 \\
20.6 \\
15.5\end{array}$ & $\begin{array}{l}2.7 \\
1.4 \\
2.3 \\
7.7 \\
8.6 \\
2.4 \\
7.0 \\
2.4 \\
8.3 \\
5.9\end{array}$ \\
\hline
\end{tabular}

height elevated layers (between 500 and $1000 \mathrm{~m}$ above the surface) may be included in either of the two groups (L and $\mathrm{HE}$, or LE and $\mathrm{GB}$ ) without any substantial change. The figures for the combination of all profile types show that for this path the overall fadeout incidence is 36.7 percent, and the overall fadeout percentage is 5.9 percent, both for the operationally important $10-\mathrm{db}$ fadeouts.

Figure 8 shows the dependence of fadeout time, as defined above for 5-db fadeouts, on the refractive index profile parameters $h_{1}, h_{1}+h_{2}$, and $\Delta N_{2}$, where $h_{1}$ is the elevation of the base of the layer above the surface (in this case, mean sea level), $h_{1}+h_{2}$ is the elevation of the top of the layer with $h_{2}$ indicating the thickness of the layer, and $\Delta N_{2}$ the refractive index gradient within the layer. The same data were used in this study, as before (for table 7), except that only 5 -db fadeouts were considered. The graphs were obtained by an averaging procedure described by Barsis and Johnson [1961], resulting in mean percentage fadeout time, and the standard deviations of the individual mean values indicated by the vertical "wings" about the points shown.

The abscissa scale on figure 8 (a) represents the height $h_{1}$ of the layer base. The point at $h_{1}=0.49$ $\mathrm{km}$ indicates 9.6 percent fadeout time and represents the mean value of percent fadeout time observed for all hours when the layer height, $h_{1}$, was between 0.4 and $0.6 \mathrm{~km}$. To illustrate some special cases, the point $h_{1}=0$ corresponds to the mean value of percent fadeout time for all occurrences of a ground-based layer. The value $h_{1}=1.82 \mathrm{~km}$ represents the average for all layer heights in excess of $1.4 \mathrm{~km}$, and the value corresponding to linear profiles is plotted at the far right of the graph, as it may be considered a limiting value with $h_{1}$ approaching infinity.

In a similar way the fadeout time percentage has been plotted versus the elevation of the top of the layer $\left(h_{1}+h_{2}\right)$ on figure $8(\mathrm{~b})$. Here the linear profile may be considered a limiting case if $h_{1}+h_{2}$ approaches zero as well as infinity.

On figure 8(c) the abscissa scale represents the refractive index gradient $\Delta N_{2}$ within the layer. This scale was divided into intervals of $20 \mathrm{~N}$-units for the averaging process. This graph does not include values corresponding to linear profiles, because by definition of the profile types a linear profile does not have a value of $\Delta N_{2}$ associated with it. 

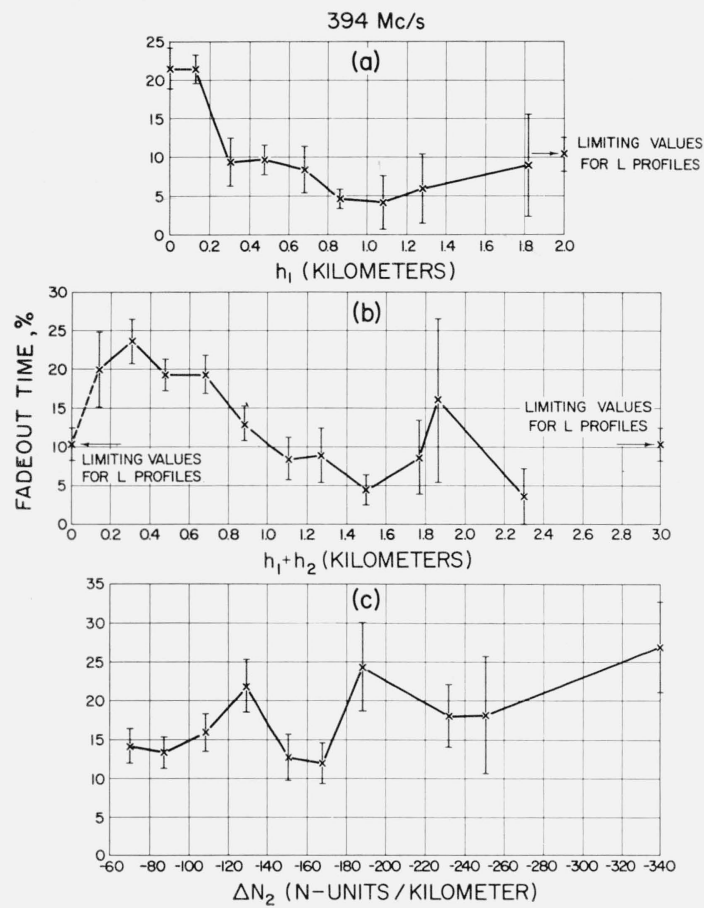

Figure 8. Percent fadeout time as a function of profile characteristics for San Nicolas Island-Laguna Peak path (Nov. 1955-Oct. 195\%; 394 Mc/s).

The graphs of figure 8 provide more detailed information on the dependence of fadeout time on layer characteristics, whereas the results shown previously in table 7 apply only to a general classification of the layers. Figure $8(\mathrm{a})$ shows quite clearly that the fadeout time percentage is greatest for ground-based and very low layers (below $200 \mathrm{~m}$ above the surface). The dependence on the height of the top of the layer, shown in figure 8(b), indicates maximum fadeout time for heights $h_{1}+h_{2}$ below $800 \mathrm{~m}$. Both terminals are well below this height, suggesting that a well-defined discontinuity in the refractive index profile structure favors the occurrence of fadeouts if the ray paths penetrate the discontinuity. The second maximum on figure $8(\mathrm{~b})$ appears to be less significant due to the wide spread of the data.

Fadeout time dependence on the refractive index gradient $\Delta N_{2}$ within the layer is not significant, as shown by figure 8(c). In general, very little correlation was found to exist between transmission loss values for this path derived from measurements and values calculated using the two-ray geometric optics model and depending on the magnitude of the refractive index gradient. It is thus unlikely that phase interference phenomena based on the two-ray model are responsible for the majority of the observed fadeouts. As a result of this study, it is much more apparent that fadeout time and fadeout incidence are strongly dependent on the existence of refractive index profile discontinuities. They are also a function of layer height above the surface. Layers which start at elevations substantially above the path terminals do not seem to produce as many fadeouts as the ones which occur at elevations comparable to the height of the ray paths.

In addition to the $394 \mathrm{Mc} / \mathrm{s}$ data obtained since November 1955 on the San Nicolas Island-Laguna Peak Summit path, some data were recorded at frequencies near 100 and $250 \mathrm{Mc} / \mathrm{s}$ from November 1957 until January 1958 and from April to the beginning of August 1959. Furthermore, an additional receiving site, called the "Van" location, was established on Laguna Peak at an elevation of $254 \mathrm{~m}$ above mean sea level, which is still within the radio horizon of the transmitting antenna location. This site was in use between April and August 1959. A $394 \mathrm{Mc} / \mathrm{s}$ receiver was installed there, permitting comparison of signal characteristics at the same frequency, but for different grazing angles (2.0 and $3.6 \mathrm{mr}$, respectively). For all frequencies, vertical polarization with corner-reflector antennas was used.

Very little meteorological data could be obtained for these two recording periods, so that the evaluation of the data will be restricted to studies of the carrier frequency and antenna height (or grazing angle) dependence of the fadeouts without any correlation with meteorological data.

Fadeout incidence (here the number of fadeouts in a 90-day period) for the summer measurement period mentioned above is shown in figure 9 as a function of carrier frequency. The graph shows points for 5-, 10-, 15-, and 20-db fadeouts at the three frequencies, arbitrarily connected by straight lines. Data for the "Van" location have also been included. There is frequency dependence, expecially when comparing 250 and $400 \mathrm{Mc} / \mathrm{s}$. The grazing angle dependence is quite pronounced by the separation of the "Van" points from the solid lines which denote the "Summit" data. It should also be noted that there were more than one hundred $20-\mathrm{db}$ fadeouts in a 90-day summer period at $400 \mathrm{Mc} / \mathrm{s}$, which would correspond to more than one such fadeout per day if evenly distributed.

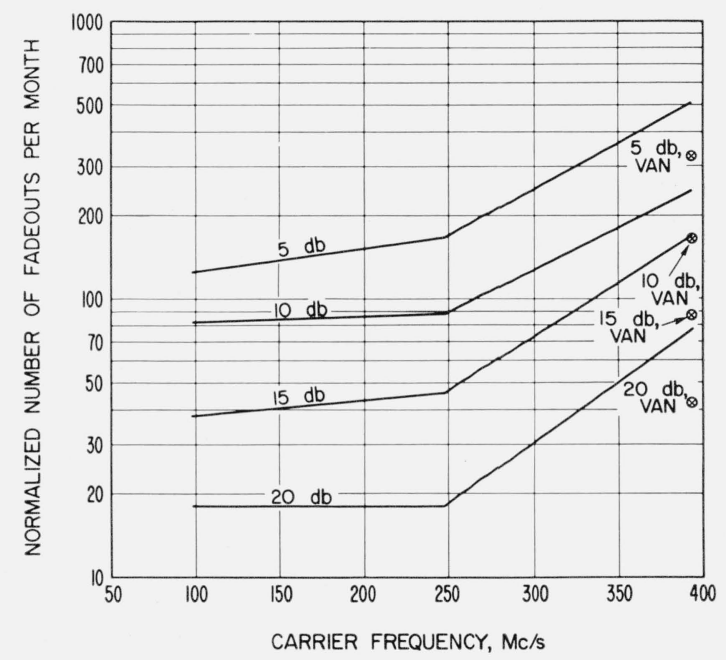

Figure 9. Frequency dependence of fadeout incidence for San Nicolas Island-Laguna Peak path (Apr.-Aug. 1959). 
Examples of the diurnal variations of the spacewave fadeout incidence observed on the three frequencies are shown in figure 10. Here the summer data are used (April-August 1960), and the data are separated into the four summer time blocks [Norton et al., 1955], corresponding to early-morning, mid-morning, afternoon, and evening hours. The ordinate values show the number of fadeouts per hour, and the data are grouped by frequency (for both the "Van" and the "Summit" locations), time blocks, and depth of fadeouts. It is seen that at $400 \mathrm{Mc} / \mathrm{s}$ there are generally more fadeouts at the "Summit" location (which corresponds to a larger grazing angle) than at the "Van." A slight diurnal trend is discernible for all data with the fadeout incidence greatest for the evening hours (time block 6). This diurnal trend is different from the one shown on figure 2 for the Mt. Wilson-Point Loma path where the greatest fadeout incidence appeared in the early afternoon hours (time blocks 2 and 5 ).

An analysis of fadeout duration is shown in figure 11 in the form of cumulative distributions of the duration of $10-\mathrm{db}$ fadeouts. The curves are labeled with the total number of the $10-\mathrm{db}$ fadeouts observed in each case, and are coded to denote the three different frequencies and two paths used. The appearance of figure 11 suggests a log-normal distribution of fadeout durations, just as was observed on figures 4 and 5 .

The median durations of 10 -db fadeout read from figure 11 are compared with similar values for the Mt. Wilson-Point Loma path (taken from fig. 5 and table 2) in the following tabulation.

TABLE 8. Median durations of 10-db fadeouts

\begin{tabular}{|c|c|c|c|c|}
\hline \multirow{2}{*}{$\begin{array}{c}\text { Carrier } \\
\text { frequency }\end{array}$} & \multirow{2}{*}{ Path } & \multicolumn{3}{|c|}{ Fadeout duration in minutes } \\
\hline & & Winter & Summer & All data \\
\hline $\begin{array}{l}M c / s \\
100 \\
138 \\
250 \\
400 \\
400 \\
1250\end{array}$ & $\begin{array}{l}\text { Point Mugu } \\
\text { Mt. Wilson } \\
\text { Point Mugu } \\
\text { Point Mugu (Summit) } \\
\text { Point Mugu (Van) } \\
\text { Mt. Wilson }\end{array}$ & 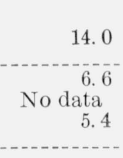 & $\begin{array}{l}9.1 \\
-7.0 \\
3.4 \\
3.5\end{array}$ & $\begin{array}{l}5.7 \\
-1 . \\
-1.6\end{array}$ \\
\hline
\end{tabular}

Although the data from the Mount WilsonPoint Loma path were not broken down into the "winter" and "summer" classification, and the Point Mugu data include shorter fadeouts, both sets can be used to establish a common trend of frequency dependence. As expected, fadeout time shows a trend with frequency opposite to the trend of fadeout incidence shown on figure 9. In general, more fadeouts are counted in a given time period for higher frequencies, but they are of shorter duration.

Figure 11 also shows that the curves for the "Summit" and the "Van" locations, both for 394 $\mathrm{Mc} / \mathrm{s}$, are almost coincident. It is concluded that no effects of the grazing angle on fadeout duration have been found in the data analyzed here.

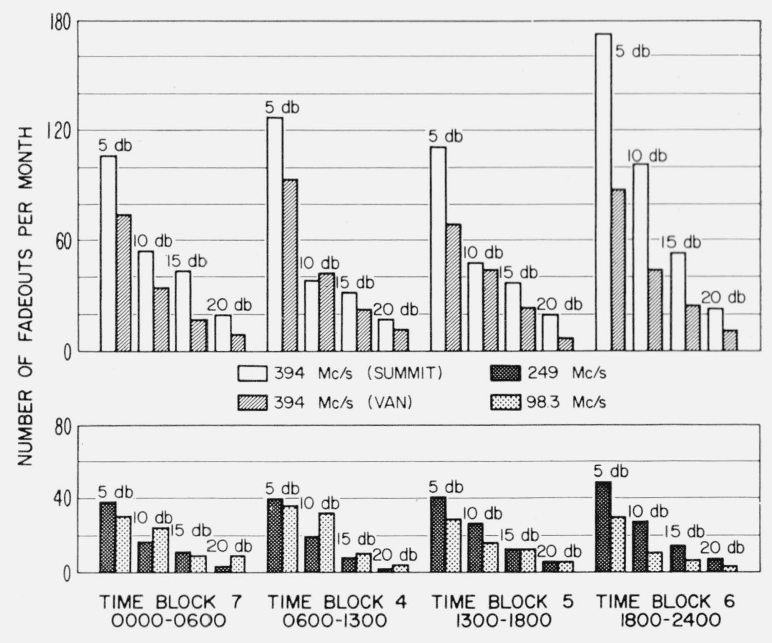

Figure 10. Diurnal variations of prolonged space-wave fadeouts for San Nicolas Island-Laguna Peak path (Apr.Aug. 1959).

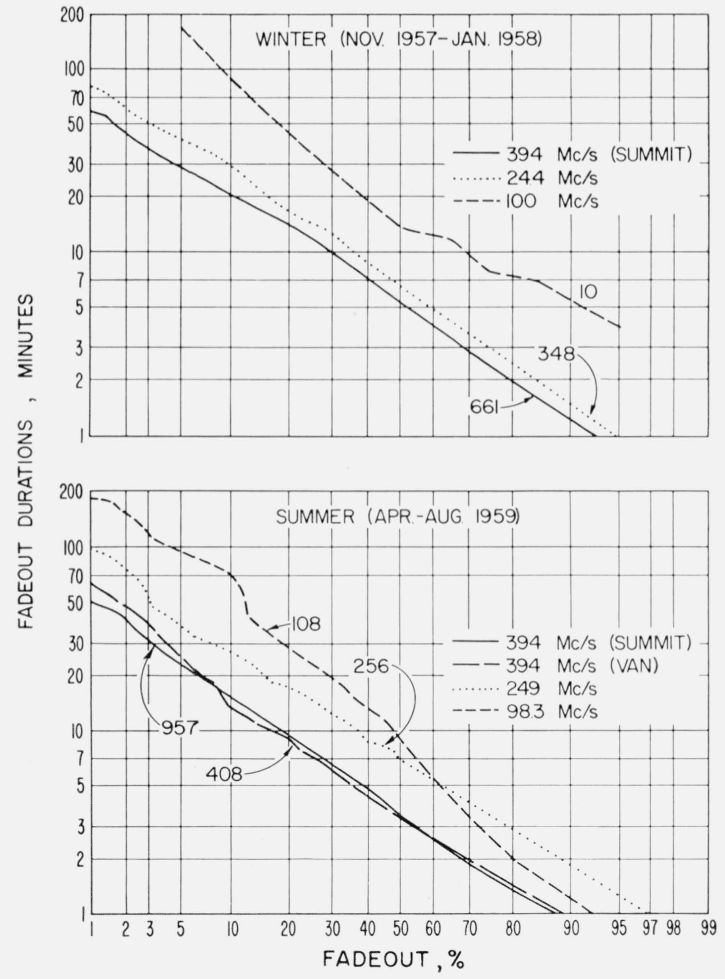

Figure 11. Frequency dependence of cumulative distributions of 10-db fadeouts for San Nicolas Island-Laguna Peak path.

\section{Fadeouts on a Knife-Edge Diffraction Path}

During 1959 and 1960, transmission loss measurements were made over a $223-\mathrm{km}$ path in Colorado, using continuous wave signals on $751 \mathrm{Mc} / \mathrm{s}$. The top of Pikes Peak, $4292 \mathrm{~m}$ above mean sea level, 

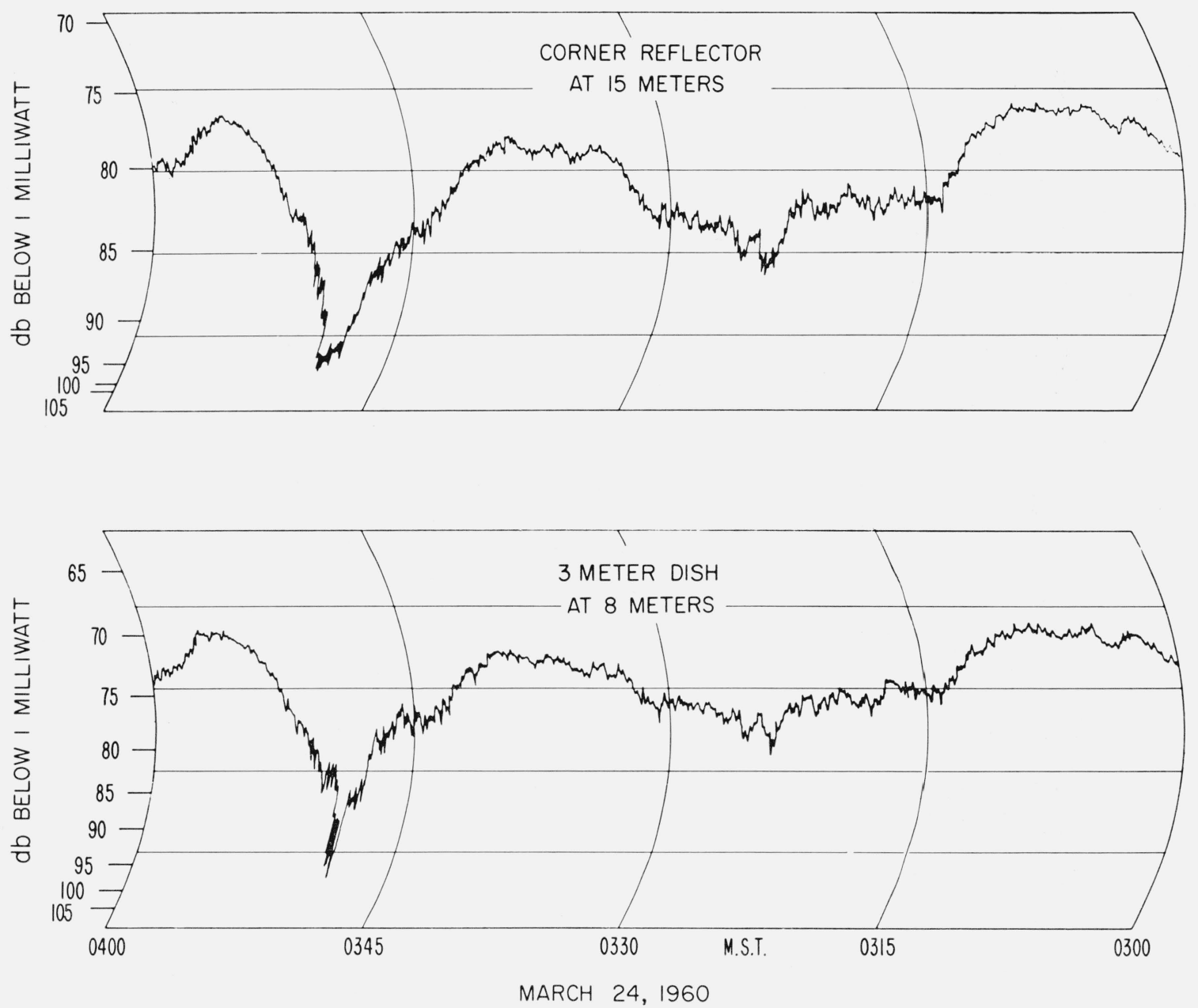

Figure 12. Recording chart samples for Colorado obstacle gain path; $751 \mathrm{Mc} / \mathrm{s}$.

forms the diffracting knife-edge. The transmitting installation is located near Beulah (southwest of Pueblo), and the receiving installation is on Table Mesa, north of Boulder. The path profile, a complete description of the equipment used and the measurements performed are contained in a separate paper [Barsis and Kirby, 1961]. The data discussed here are concerned with prolonged space-wave fadeouts observed on this path on two receiving antennas, spaced vertically by approximately 20 wavelengths.

Although this path is not "optical" (terminals within each other's radio horizon), the fading characteristics may be compared with the ones previously described, because the received field may be considered as the vector sum of up to four rays, each of which is modified in magnitude and phase by the diffracting knife-edge [Dickson et al., 1953]. Figure 12 shows a typical sample of field strength records obtained simultaneously from the two receiving antennas. The fadeouts in this case appear to be extremely well correlated, just as in the case of the Cheyenne Mountain-Karval path (fig. 6). Here, too, the small, superimposed, more rapid signal variations have not been considered in the analysis.
Figure 12 suggests that fadeout phenomena on this obstacle-gain path are similar to the ones observed on the within-the-horizon paths, and that vertical space diversity would be of little use due to the apparent correlation of the fadeouts observed on the two antennas.

An analysis of fadeouts was made by data recorded using two spaced receiving antennas; a corner reflector, mounted $15 \mathrm{~m}$ above ground, and a $3-\mathrm{m}$ parabolic reflector, $8 \mathrm{~m}$ above ground. ${ }^{1}$ The transmitting antenna was a $4.5-\mathrm{m}$ parabolic reflector mounted $7 \mathrm{~m}$ above ground level. Horizontal polarization was used for all tests. Continuous recording's were available during a number of fiveday periods between December 1959 and September 1960 .

The diurnal trend in the fadeout incidence observed at various levels below the median for each recording period $^{2}$ is shown on figure 13 , with the

1 During two of the 5-day recording periods (in June), the corner reflector was at an elevation of $23 \mathrm{~m}$ above ground. No material difference in the characteristics of the fadeouts at the two elevations was found.

2 This reference level was chosen in lieu of monthly medians, as data for any 2 This reference level was chose
full mont h were not available. 
ordinate indicating the number of fadeouts per hour for each time block. 5-db fadeouts are much more frequent than expected from a comparison with the other levels. There are only comparatively few $10-\mathrm{db}$ fadeouts during the winter.

While the 10-db fadeouts show an afternoon (time block 5) minimum similar to the Cheyenne Mountain-Karval path (see sec. 2), 5-db fadeout incidence shows a maximum for time block 4 corresponding to the morning hours. Also of interest is the minimum for the 5-db fadeouts in time block 8, corresponding to night and early morning hours during winter. No significant difference in fadeout incidence exists for the two antenna heights represented. Fadeout incidence is somewhat greater on the average for the higher antenna, although the difference is not as prominent as was seen for the three antenna heights of Karval.

The data suggest the possibility of two separate propagation mechanisms, one producing only 5 -db fadeouts, and the other responsible for the deeper fadeouts. Comparison of the diurnal trend with data from the Karval path suggests that the second mechanism is similar to the one causing fadeouts on within-the-horizon paths.

The cumulative distributions of fadeout durations for this path are shown on figure 14 for both antennas. Here, fadeout durations as short as $0.1 \mathrm{~min}$ could be measured. Table 9 is a tabulation of median fadeout durations taken from figure 14 .

TABLE 9. Median fadeout durations for Colorado ObstacleGain Path, $751 \mathrm{Mc} / \mathrm{s}$

\begin{tabular}{|c|c|c|c|c|}
\hline \multirow{3}{*}{$\begin{array}{l}\text { Level, } \\
\text { db below } \\
\text { hourly } \\
\text { median }\end{array}$} & \multicolumn{4}{|c|}{ Median fadeout duration, minutes } \\
\hline & \multicolumn{2}{|c|}{ Corner reflector } & \multicolumn{2}{|c|}{ 3-m dish } \\
\hline & Winter & Summer & Winter & Summer \\
\hline $\begin{array}{r}5 \\
10 \\
15\end{array}$ & $\begin{array}{r}0.58 \\
.60\end{array}$ & $\begin{array}{r}0.46 \\
.44 \\
.28\end{array}$ & $\begin{array}{r}0.31 \\
.23\end{array}$ & $\begin{array}{r}0.32 \\
.27 \\
.35\end{array}$ \\
\hline
\end{tabular}

It is seen that the median fadeout at the 5-and 10-db levels is of longer duration for the corner reflector antenna, which is at a greater height. For the corner reflector antenna, the fadeouts are longer in winter than in summer; whereas for the dish no seasonal trend is observed. Of interest here is the much shorter duration of the median fadeouts compared to those observed on within-the-horizon paths (see table 2). This is partially due to the inclusion of fadeouts as short as $0.1 \mathrm{~min}$ in the Pikes Peak data and supports the idea of additional propagation mechanisms influencing the fadeout statistics on knife-edge diffraction paths.

A somewhat different analysis of fadeout durations is contained in figure 16 of a paper by Barsis and Kirby [1961]. There, the distributions of fadeout durations for time periods of several hours were obtained at a number of arbitrary levels below the median, together with the distributions of highsignal durations for levels above the median. The asymptotic extensions towards a zero fade, or high

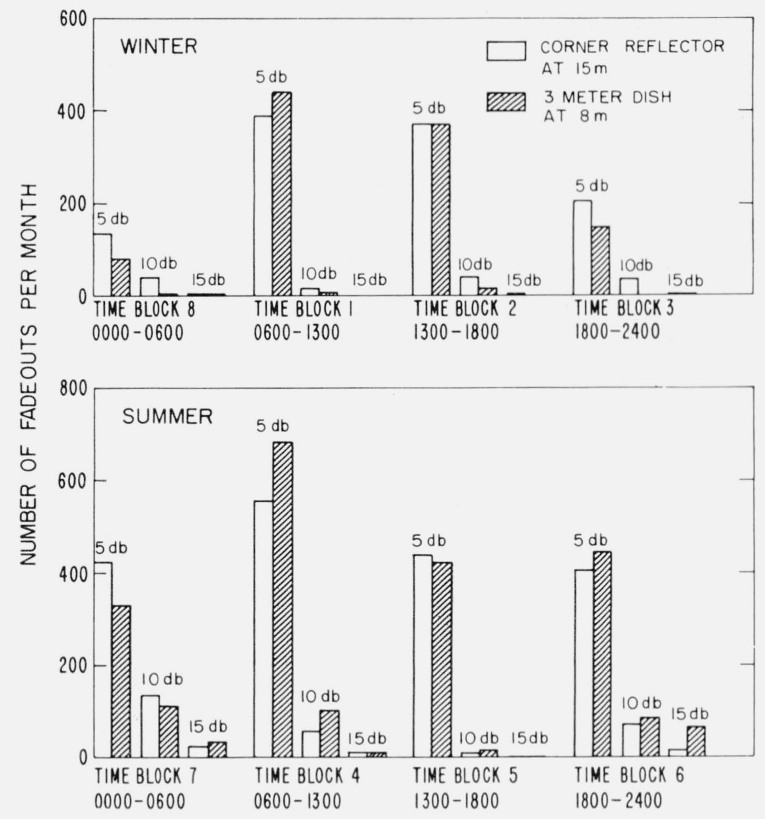

Figure 13. Diurnal variations of prolonged space-wave fadeouts for Colorado obstacle-gain path (Dec. 1959-Sept. 1960; $751 \mathrm{Mc} / \mathrm{s})$.

signal duration of cumulative distribution curves resulting from this analysis, become the distribution of instantaneous signal levels for the period of record analyzed.

The effectiveness of vertical space diversity for this path may also be evaluated by the number of fadeouts occurring simultaneously on both antennas in relation to the total number of observed fadeouts. This is the same type of evaluation performed for the three vertically spaced antennas at Karval (see sec. 2). Results are given in table 10 using 5 -db and $10-\mathrm{db}$ fadeouts. This study includes the two June recording periods, with the $15-\mathrm{m}$ separation between the antennas, so that vertical spacings of 17.5 and 37.5 wavelengths are both represented. Fadeouts were classified as occurring simultaneously on both antennas when any portion of them coincided in time.

The absence of simultaneous 10-db fadeouts during all winter hours, and during the summer afternoon hours, reflects the small total number of such fadeouts observed on either antenna. Also, small errors in the timing of the recording charts may have an appreciable effect on judging whether short fadeouts are simultaneous.

The data in table 10 show that a greater probability for simultaneous fadeouts exists during the summer months, with a clear maximum during the night and early morning hours. The percentages obtained here are on the same order of magnitude as shown for the three Karval antennas described in section 2 above, and listed in more detail on table 4 of the original study [Barsis and Johnson, 1961]. 



2.
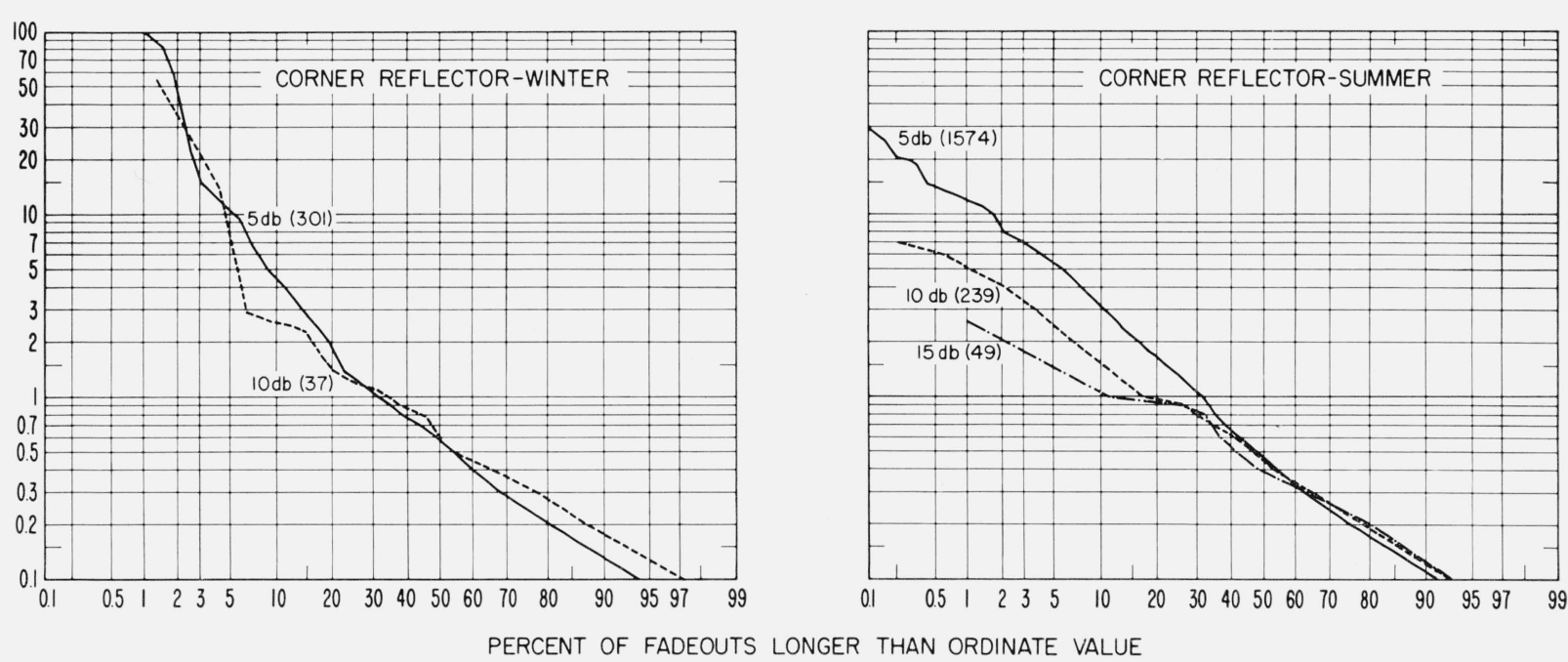

Figure 14. Cumulative distributions of fadeout durations for Colorado obstacle-gain paths.

TABLE 10. Statistics of fadeouts observed simultaneously on both antennas for the Pikes Peak Obstacle-Gain Path, 751 $\mathrm{Mc} / \mathrm{s}$

\begin{tabular}{|c|c|c|}
\hline Time blocks & $\begin{array}{l}\text { Perc } \\
\text { occurr }\end{array}$ & $\begin{array}{l}\text { fades } \\
\text { nultane- }\end{array}$ \\
\hline \multirow{2}{*}{$\begin{array}{l}\text { Winter: } \\
\qquad \begin{array}{l}8(0000-0600) \\
1(0600-1300) \\
2(1300-1809) \\
3(1800-2400)\end{array}\end{array}$} & $5 \mathrm{db}$ & $10 \mathrm{db}$ \\
\hline & $\begin{array}{l}48.3 \\
32.5 \\
44.5 \\
27.1\end{array}$ & \\
\hline $\begin{array}{l}\text { All hours, } \\
\text { winter }\end{array}$ & 37.6 & \\
\hline $\begin{array}{l}\text { Summer: } \\
7 \quad(0000-0600) \\
4 \quad(0600-1300) \\
5 \quad(1300-1800) \\
6(1800-2400)\end{array}$ & $\begin{array}{l}76.1 \\
59.6 \\
35.6 \\
59.7\end{array}$ & $\begin{array}{r}42.0 \\
28.6 \\
24.2\end{array}$ \\
\hline $\begin{array}{l}\text { All hours, } \\
\text { summer }\end{array}$ & 58.8 & 24.9 \\
\hline
\end{tabular}

\section{Conclusions}

A comparison of fadeout characteristics for different climatic areas was given in the discussion of the data obtained. Some noticeable effects are the very definite lack of fadeouts during daytime hours for the Karval path, and the absence of any pronounced seasonal variations for Pacific Coast data, as far as investigated. In contrast to the maximum fadeout incidence for the Karval path at night, fewer diurnal variations appear on the Pikes Peak obstacle-gain path.

Diurnal and seasonal trends in the occurrence of fadeouts similar to the ones observed at Karval were reported from measurements at $1300 \mathrm{Mc} / \mathrm{s}$ over an $82-\mathrm{km}$ overland path within the radio horizon, located in East Germany [Kuehn, 1957]. Despite the difference in the general climatology, the low-level modifications of the refractive index structure which are most likely to produce fadeouts appear to have 
similar diurnal and season trends in both regions. Kuehn's data, like the ones obtained at Karval, show minimum occurrence of fadeouts around the noon hour, strong maxima at night, and also substantially more fadeouts during the summer months.

The lack of fadeouts at the lower frequencies over the Colorado paths, as contrasted with the relatively large number observed at $138 \mathrm{Mc} / \mathrm{s}$ for the Mt. Wilson path, and at $100 \mathrm{Mc} / \mathrm{s}$ for the Point Mugu path, is an indication of the effects of climatic differences between the two areas. The nocturnal duct which constitutes a plausible cause for the observed fadeout phenomena at Karval [Bean, 1954] is relatively shallow and is therefore less likely to affect the lower frequencies. However, ducts and groundbased layers of sufficient thickness to affect lower frequencies are present in the maritime climate of Southern California. This was indicated by the analysis of the Point Mugu data. The occurrence of such layers in Southern California is not restricted to nighttime hours and is more likely a result of the almost always present subsidence inversion.

Anderson and Gossard [1953 a and b] have studied the effects of nocturnal and oceanic ducts on UHF propagation, using largely unpublished data from the Cheyenne Mountain program and data obtained from experiments in the Irish Sea [McPetrie and Starnecki, 1948]. Their studies were principally concerned with the enhancement of field strength on beyond-the-horizon paths produced by ducts, and with the analysis of the degree of enhancement as a function of meteorological parameters. Bean [1954] has shown that the occurrence of fadeouts on the within-the-horizon Cheyenne Mountain-Karval path is usually associated with field strength enhancement on the beyond-the-horizon Chevenne MountainHaswell path. Data from the latter path are used in one of the papers by Anderson and Gossard [1953a].

The results shown here confirm the principal dependence of fadeout phenomena on ground-based ducts. Observed differences between continental and maritime areas are due to the difference in the thickness of layers, their height above ground, and the diurnal and seasonal trends in their occurrence. Thus fadeout phenomena are, at least indirectly, a function of climate.

The effects of vertical space diversity have been discussed for both Colorado paths in sections 2 and 5 . It appears that fadeouts are reasonably well correlated at antenna spacings which might be practical for diversity arrangements, and thus impair the effectiveness of vertical space diversity for line-of-sight paths as well as for obstacle-gain paths.

The two antennas on Laguna Peak have too large a vertical separation to consider such an arrangement a practical diversity system. The experiment was designed in this case to study the effect of the grazing angle on fadeouts. Although results are not very pronounced, there is a tendency for more fadeouts on the summit of Laguna Peak, representing a greater elevation and a greater grazing angle (see fig. 9). This result is also somewhat supported by the Colorado height-gain studies, where substantially more fadeouts were observed at the higher antennas, at least for the Cheyenne Mountain-Karval path.

The most important result of these measurements is the recognition of space-wave fadeouts as an important phenomenon in line-of-sight or related propagation characteristics, especially at frequencies above $400 \mathrm{Mc} / \mathrm{s}$. The phenomenon is observed whenever the refractive index profile has strong low-level modification, regardless of climatic conditions and physical causes of the modification. Space-wave fadeouts bave to be taken into account in the design of communication systems, because of the relatively long and large drops in signal level. Studies performed so far show that vertical space diversity is not effective in compensating for all fadeouts because of the observed degree of correlation. Experiments on correlation, using horizontally spaced antennas or frequency diversity, are yet to be performed.

In dealing with an extensive measurement program of this type it is not possible to acknowledge the contributions of individuals. Data collection and evaluation was performed by the Cheyenne Mountain Field Station (partially with the support of the Air Navigation Development Board), the Tropospheric Measurement Section, and the PropagationTerrain Effects Section of the National Bureau of Standards. Also acknowledged is the assistance of the Navy Electronics Laboratory, San Diego, Calif., and of the Naval Air Missile Test Center, Point Mugu, Calif., in obtaining and supplying data and equipment, and in doing analysis work. Support from the U.S. Army Signal Research and Development Laboratories in Ft. Monmouth, N.J., facilitated compilation of the original publication [Barsis and Johnson, 1961] and of this paper.

The authors thank B. R. Bean, E. J. Dutton, R. S. Kirby, and K. A. Norton for their review and suggestions, and J. B. Smyth for drawing their attention to the work by Anderson and Gossard.

\section{References}

Anderson, L. J., and E. E. Gossard, Prediction of the nocturnal duct and its effect on UHF, Proc. IRE 41, No. 1, 136-139 (Jan. 1953).

Anderson, L. J., and E. E. Gossard, Oceanic duct and its effect on microwave propagation, Nature 17\%, 298-300 (Aug. 1953).

Barsis, A. P., and F. M. Capps, Effect of super-refractive layers on tropospheric signal characteristics in the Pacific coast region, IRE 1957 WESCON Convention Record, Part 1, 116-133 (1957).

Barsis, A. P., J. W. Herbstreit, and K. O. Hornberg, Cheyenne Mountain tropospheric propagation experiments, NBS Circ. 554 (Jan. 1955).

Barsis, A. P., and M. E. Johnson, Prolonged space-wave fadeouts in tropospheric propagation, NBS Tech. Note 88 (Feb. 1961).

Barsis, A. P., and R. S. Kirby, VHF and UHF signal characteristics observed on a long knife-edge diffraction path, J. Research NBS 65D (Radio Prop.) No. 5, 437-488 (Sept.Oct. 1961).

Bean, B. R., Prolonged space-wave fadeouts at $1046 \mathrm{Mc}$ observed in Cheyenne Mountain propagation program, Proc. IRE 42, No. 5, 848-853 (May 1954). 
Bean, B. R., L. P. Riggs, and J. D. Horn, Synoptic study of the vertical distribution of the radio refractive index, $J$. Research NBS 63D (Radio Prop.) No. 1, 249-254 (Sept.Oct. 1959).

Dickson, F. H., J. J. Egli, J. W. Herbstreit, and G. S. Wickizer, Large reductions of $\mathrm{VHF}$ transmission loss and fading by the presence of a mountain obstacle in beyond-line-ofsight paths, Proc. IRE 41, No. 8, 967-969 (Aug. 1953). A discussion of this paper is given by J. H. Crysdale in Proc. IRE 43, No. 5, 627 (May 1955).

Kuehn, U., Ein Beitrag zur Kentniss der Ausbreitungsbedingungen bei $1.3 \mathrm{GHz}$ nach Messungen an einer
Uebertragungsstrecke mit optischer Sicht, Tech. Mitt. (B.R.F.) 1, No. 1, 4-10 (Oct. 1957), Berlin-Adlershof (East Germany).

McPetrie, J. S., and B. Starneckie, Low-level atmospheric ducts, Nature 162, 818 (Nov. 1948).

Norton, K. A.,P. L. Rice, and L. E. Vogler, The use of angular distance in estimating transmission loss and fading range for propagation through a turbulent atmosphere over irregular terrain, Proc. IRE 43, No. 10, 1488-1526 (Oct. 1955).

(Paper 66D6-227) 